\title{
Fruit characteristics of six candidate olive cultivars
}

\author{
Yasin Ozdemir ${ }^{1}$, Nesrin Aktepe Tangu ${ }^{1}$, Aysun Ozturk', \\ Mehmet Emin Akcay ${ }^{l}$, Sezai Ercisli ${ }^{2 *}$ \\ ${ }^{1}$ Ataturk Central Horticultural Research Institute, Yalova, Turkey \\ ${ }^{2}$ Department of Horticulture, Agricultural Faculty \\ Ataturk University, Erzurum, Turkey
}

\begin{abstract}
Some important physical, chemical and sensory characteristics of raw and processed olives (processed by the same scratched table olive process) were investigated. In the study, six candidate cultivars obtained by crossbreeding and one standard cultivar ('Domat') grown together in an olive breeding and observation plot in the Ataturk Central Horticultural Research Institute in Turkey were investigated. Fruit weight and flesh-to-seed ratio of fresh raw olives ranged from 5.18 to $7.65 \mathrm{~g}$ and 4.8 to 6.3, respectively. LT011 had the highest fruit weight, whereas LT001 and LE001 had the highest flesh-to-seed ratio. Total phenolic content and antioxidant activity of the produced table olives were estimated between 102 and $141 \mathrm{mg}$ gallic acid equivalents per $100 \mathrm{~g}$ fresh weight, and 13.4 and $14.9 \mu \mathrm{mol}$ Trolox $100 \mathrm{~g}^{-1}$, respectively. Fruits of LT001 had higher appearance, taste, bitterness and general appreciation scores than the others. LT001 showed a lesser loss of oleuropein absorbance and antioxidant activity than the others during processing. The results of this study revealed that LE001, LT001 and LT011 had superior characteristics for the production of scratched green table olives.
\end{abstract}

Keywords: antioxidant activity genotype, oleuropein, sensory evaluation, total phenolics

\section{INTRODUCTION}

The history of plant breeding is as old as the history of mankind. In the beginning, gardeners and farmers widely practised plant breeding worldwide, and in recent years, it has been practised by professional plant breeders, government agencies, industry associations and research centres. In this context, hybridization, or cross-breeding, has been practised for a long time (Ercisli, 2004; Benjak et al., 2005; Yazici and Sahin, 2016).

Increasing consumer awareness of the human health components of fruits through social media has led to an increase in the interest in fruits. These compounds, called phytochemicals, have a positive effect on the internal quality properties of fruits. Thus, in recent years, the aim of fruit breeding has changed considerably, and to obtain cultivars that have a high phytochemical content has become very important (Kamiloglu et al., 2009; Tosun et al., 2009; Milivojevic et al., 2012; Mikulic-Petkovsek et al., 2013, 2015).

Olive cultivation is located mainly in the Mediterranean Basin. In most of the Mediterranean countries, olive (Olea europaea subsp. europaea var. europaea) cultivation has been practised since the beginning of human civilization. It is the main fruit species with a high economic value in the region. The countries of the Mediterranean Basin have unusually rich olive germplasm resources, and each olive-growing country has numerous olive cultivars (Baldoni and Belaj, 2009; Sakar and Unver, 2016; Sorkheh and Khaleghi, 2016). However, in general,

*Corresponding author. 
olive cultivars exhibit lower genetic diversity than their wild relatives (Belaj et al., 2010).

More recently, the numbers of new olive cultivars derived under planned breeding programmes have increased (Jenks and Bebeli, 2011). The cultivar is the most important factor determining the quality of table olives. Thus, many researchers intend to develop new high quality olive cultivars (Bellini et al., 2008; León et al., 2008). Fruit yield, fruit weight, flesh/stone ratio, fruit shape, stone shape, oil content, sensory characteristics and flesh texture have been reported as significant and useful characteristics for the selection of candidate table olive cultivars in breeding programmes (Kailis and Harris, 2007; Rallo et al., 2012). The first olive cross-breeding programmes started in the mid-1960s and continued in the following years (Jenks and Bebeli, 2011). In Turkey, the first olive cross-breeding programme was started in 1990 at the Ataturk Central Horticultural Research Institute, where 1500 olive genotypes have been obtained by crossing Turkish, Spanish and Italian high-quality table olive cultivars. From among these 1500 olive genotypes, 6 superior genotypes have been selected as new candidate cultivars for green table olive production according to their high productivity, resistance to diseases, low periodicity and large and homogeneous green fruits. Natural green table olives are mostly made by scratched olive production in the world (Kailis and Harris, 2007). On this account, this research was aimed to determine the characteristics of raw and scratched green table olive fruits of these candidate cultivars and define their suitability for the production of scratched green table olives.

\section{MATERIAL AND METHODS}

\section{Plant material}

In this study, olives from 6 candidate cultivars and the cultivar 'Domat' were evaluated. Their codes, parents and maturity indices are given in Table 1. They come from crosses of foreign cultivars: Belle d'Espagne (Italian cultivar) and Lucas (Spanish cultivar), and Turkish cultivars: Tavşanyüreği and Edinciksu. The trees were planted at $1.5 \mathrm{~m} \times 3 \mathrm{~m}$ in the olive genotype observation orchard of the Ataturk Central Horticultural Research Institute (Yalova, Turkey). The genotypes had been chosen by breeding researchers on the basis of their high productivity, resistance to diseases, low periodicity and large and homogeneous green fruits according to the results of a national cross-breeding project (Obtaining New Olive Varieties by Crossing, 19902018). The maturity index was determined on 100 randomly selected olives in each sample to obtain a numerical value for the olive sample appearance. The olives were sorted into categories using the following criteria: $0=$ skin is a deep or dark green colour; 1 = skin is a yellow or yellowish-green colour; $2=$ skin is a yellowish colour with reddish spots; 3 = skin is a reddish or light violet colour; $4=$ skin is black and the flesh is completely green; $5=$ skin is black and the flesh is a violet colour half-way through; $6=$ skin is black and the flesh is a violet colour almost through to the stone; $7=$ skin is black and the flesh is completely dark. The total number of olives in each category was counted and recorded. The following equation was then applied to determine the maturity index (Hassan et al., 2011):

Maturity Index $=\frac{\left(0 \times n_{0}\right)+\left(1 \times n_{1}\right)+\left(2 \times n_{2}\right)+\left(3 \times n_{3}\right)}{+\left(4 \times n_{4}\right)+\left(5 \times n_{5}\right)+\left(6 \times n_{6}\right)+\left(7 \times n_{7}\right)} \times 100$

where $n_{i}$ is the number of fruits with the score of i. Olives were randomly handpicked in 2013-2014 and 2014-2015, and raw olives were divided into 2 groups for each sample. One group of raw olives was analyzed and the other group was processed into table olives on the same day of harvesting.

Table 1. Codes, parents and maturity index of olive samples

\begin{tabular}{lccc}
\hline Code & Parents & $\begin{array}{c}\text { Maturity index of olives } \\
\text { harvested in 2013-2014 }\end{array}$ & $\begin{array}{c}\text { Maturity index of olives } \\
\text { harvested in 2014-2015 }\end{array}$ \\
\hline BE001 & Belle d'Espagne $\times$ Edinciksu & 1.2 & 1.4 \\
BE003 & Belle d'Espagne $\times$ Edinciksu & 1.3 & 1.2 \\
BE005 & Belle d'Espagne $\times$ Edinciksu & 1.1 & 1.2 \\
LE001 & Lucques $\times$ Edinciksu & 1.3 & 1.1 \\
LT001 & Lucques $\times$ Tavşanyüreği & 1.2 & 1.4 \\
LT011 & Lucques $\times$ Tavşanyüreği & 1.1 & 1.3 \\
Domat & - & 1.2 & 1.4 \\
\hline
\end{tabular}

Maturity index determined by the method of Hassan et al. (2011) 


\section{Method of table olive production}

Olives were processed into scratched green table olives according to the Turkish Food Codex Table Olive Communiqué (Anonymous, 2014). Olives were scratched lengthwise by cutting into the skin two times. The scratched olives were kept in water, and this water was replaced with fresh water 7 times at 2-day intervals. The scratched olives were kept in $6 \%$ brine for fermentation for 15 days. After that, the processed olives were analyzed immediately.

\section{Physical and chemical analyses}

Fruit and seed weight, flesh-to-seed ratio, fruit and seed size, colour values of the skin, texture hardness, titratable acidity, $\mathrm{pH}$, absorbance of oleuropein, water content, total phenolics and antioxidant activity of raw and processed olives were determined for each sample. Also, sensory profiles and the salt content of processed olives were determined.

Fruit weight was calculated by weighing 100 olive fruits. Flesh-to-seed ratio was calculated by dividing the flesh weight by the seed weight of 100 olive fruits. Fruit weight and flesh-to-seed ratio were determined according to the official method TS 774 (1992). Fruit and seed size (width and length) were measured with digital callipers (Series 551 Mitutoyo, Japan). Colour values of the skin were measured with a colour meter (Konica Minolta, Japan). Texture hardness was measured with a fruit hardness tester (W.O.W FRH-5, Japan). Titratable acidity, $\mathrm{pH}$ value and sodium chloride content (only for processed olives) were determined according to the official method TS 774 (1992). Water content of olive samples was determined in a conventional oven at $75 \pm 2{ }^{\circ} \mathrm{C}$ (Esti et al., 1998). The oleuropein absorbance value was determined as follows: $50 \mathrm{~g}$ of seedless olives were blended and mixed with $125 \mathrm{ml}$ of pure water and then boiled for 5 minutes and filtered under vacuum. The filter paper was rinsed with $125 \mathrm{ml}$ distilled water and placed in a beaker; the residue in the beaker was boiled again and filtered. The filtrates were combined, and made up to $200 \mathrm{ml}$ with pure water. $2.5 \mathrm{ml}$ of this filtrate was placed in a $25 \mathrm{ml}$ balloon flask and $0.5 \mathrm{ml}$ of $1 \%$ gelatin was added. This was made up to $25 \mathrm{ml}$ with acetone and $20 \mathrm{ml}$ was taken and stirred for 2 minutes with $4 \mathrm{~g}$ of $\mathrm{Al}_{2} \mathrm{O}_{3}$. The absorbance values were determined at $345 \mathrm{~nm}$ wavelength against acetone in a spectrophotometer (Shimadzu UV-1700 Pharmospec). Total phenolic content of these samples was determined by the Folin-Ciocalteu method according to Thaipong et al. (2006). The total phenolic content was calculated from the calibration curve which was prepared by using gallic acid, and the results were expressed as $\mathrm{mg}$ of gallic acid equivalents per $100 \mathrm{~g}$ dry weight. Antioxidant activity was determined by the DPPH method Usenik et al. (2007), with calculation from the calibration curve which had been prepared by using Trolox and the results were expressed as mg of Trolox equivalents per $\mathrm{kg}$ fresh weight.

\section{Sensory analysis}

The sensory profiles of the processed olives were assessed by using the sensory profile sheet developed by trained judges. A descriptive panel of ten judges was employed. The judges had been trained during a few preliminary sessions by using different samples of spontaneously fermented black table olives, in order to develop a common vocabulary for the description of the sensory attributes of table olive samples and also to familiarize themselves with the rating scales and procedures according to Aponte et al. (2010). Each attribute term was extensively described and explained to avoid any doubt about the relevant meaning. Three 1-hour sessions (4-5 samples/session) were conducted to complete the analysis. Sensory characteristics were evaluated by the panelists on a 9-point scale (9: like extremely, 8: like very much, 7: like moderately, 6: like slightly, 5: neither like nor dislike, 4: dislike slightly, 3: dislike moderately, 2: dislike very much and 1: dislike extremely). Sample preparation, serving and tasting procedures were organized according to Galán-Soldevilla and Ruiz PérezCacho (2010). The appearance and colour attributes were assessed by the panelists on the complete sample before tasting. Odour, ease of separation from the seed, taste, bitterness and, finally, general appreciation attributes were evaluated accordingly. Evaluation of odour was made by direct aspiration of the air over the tasting glass in 2 phases: in the first one, the glass was kept still to detect any possible defects and then it was shaken gently to determine the different odour attributes (GalánSoldevilla et al., 2013).

\section{Statistical analysis}

The research plan was performed according to a randomized experimental design. Three replicates were tested for each parameter and each sample, which included $1 \mathrm{~kg}$ of olives. Analysis of variance was applied with the Duncan multiple comparison test of the means $(p<0.01)$ to determine the presence of significant differences among the samples. Statistical analysis was performed by 
using the JMP v. 5.0 statistical package program (SAS Institute, Cary, N.C., USA). Different letters in the same column of the tables indicate a significant difference.

\section{RESULTS AND DISCUSSION}

High fruit weight and low seed weight are required of candidate cultivars of fruit species (Ercisli and Esitken, 2004; Saridas et al., 2016). Statistically significant differences were observed in fruit weight and flesh-to-seed ratio of olives (Tab. 2). BE001 and LT001 had advantages for registration according to the evaluation of both fruit weight and flesh/seed ratio. In this study, fruit weight and flesh-to-seed ratio were observed in the ranges 5.18-6.40 $\mathrm{g}$ and 4.8-6.4, respectively and were higher than those reported by Arji and Bahmanipour (2014) and Rallo et al. (2008). They had determined fruit weight and flesh-to-seed ratio in the ranges 1.80-4.76 g and 3.20-4.53, respectively, for the evaluated olive cultivars and candidate cultivars.

The skin colour of olives distinguishes four types according to its colour, which are green, turning colour, natural black and ripe olives (BOE, 2001). In this research, the colour values of olives which corresponded to the green colour (a values) were determined between -20.74 and -17.30 (Tab. 3). According to the $\mathrm{L}$, a and $\mathrm{b}$ colour values, BT003 and LT001 were determined as bright greenish olives. On the other hand, 'Domat' and BE005 had the lowest $\mathrm{L}$ values.

Hardness is reported as an important table olive quality criterion which attracts high consumer appreciation (Castro-Garcia et al., 2009). In this research, hardness, $\mathrm{pH}$ and titratable acidity of raw olive samples were determined to be in the ranges 420-510 g, 4.93-5.18 and 0.26-0.56\% oleic acid, respectively (Tab. 3). There were no statistically significant differences in $\mathrm{pH}$ and titratable acidity values of olive samples. However, the olive samples had significantly different hardness values: BE001 had the highest (510 g) and BE005 had the lowest $(420 \mathrm{~g})$ tissue hardness.

A low oleuropein absorbance value of olives was favourable for the new candidate cultivars. BE001 had statistically the same oleuropein absorbance value as 'Domat', but the others had higher values. BE001 had a markedly higher total phenolic content and antioxidant activity than the others (Tab. 4). The oleuropein absorbance value of BE003 was higher than the values for the other samples and those reported by Sahin et al. (2002) and Savas and Uylaser (2013). The water content of the raw olive samples was determined to be in the range 70.10 $-72.27 \%$ and there was no statistically significant difference in water content among the candidate olive cultivars (Tab. 4). The water content of the raw olives was higher than the range $65.22-68.18 \%$ reported by Savas and Uylaser (2013) for olives of the cultivar 'Domat'.

Large size, favourable shape and colour, high flesh-to-stone ratio, ease in releasing from seed and hard texture of fruits in the final product have been reported as desirable characteristics for the selection of new table olive cultivars (Sánchez Gómez et al., 2006). A flesh-to-seed ratio requirement of at least 5 had been reported for new candidate table olive cultivars (Varol et al., 2009). In this research, the flesh-to-seed ratio of all table olives except BE005 had a value greater than 5 . Because of the low flesh-to-seed ratio of its fruits (4.8), BE005 had a big disadvantage for selection as a new table olive cultivar (Tab. 2).

Texture hardness of green olives is one of the attributes that affects consumer acceptance and may be strongly influenced during processing (Fadda et al., 2014). Determination of hardness of the processed olive, when compared with its raw state, gives information about the extent of softening during processing (Lanza, 2013). In this study, LE001 (55.3\%) and LT001 (47.7\%) had the highest losses of hardness, whereas BE005 (26.2\%), BE003 (27.6\%) and LT011(30\%) had the lowest. The hardness of our raw olive samples was found to be similar to the values reported by Bautista-Gallego et al. (2011) (520-790 g), but the hardness of our processed olive samples was found to be higher than the values given by Fadda et al. (2014) (108 $-152 \mathrm{~g})$ and El-Soaly (2008) (223.6-249.7 g). When compared with raw olives, all of the processed olives had a lower $\mathrm{pH}$ and an increased titratable acidity due to spontaneous fermentation. Similar changes in $\mathrm{pH}$ and titratable acidity had also been reported by Panagou et al. (2011) and Bautista-Gallego et al. (2010) (Tab. 3).

The oleuropein absorbance of olives dramatically decreased after processing because the treatment involved scratching raw olives lengthwise by cutting into their skin and replacing several times the water in which the olives were kept (Ozdemir et al., 2014). This debittering method has been reported as one of the oldest debittering methods (Kailis and Harris, 2007). Debittering is a common practice of transforming raw table olives into their edible form. During the debittering process, which includes different steps, there is a significant loss 


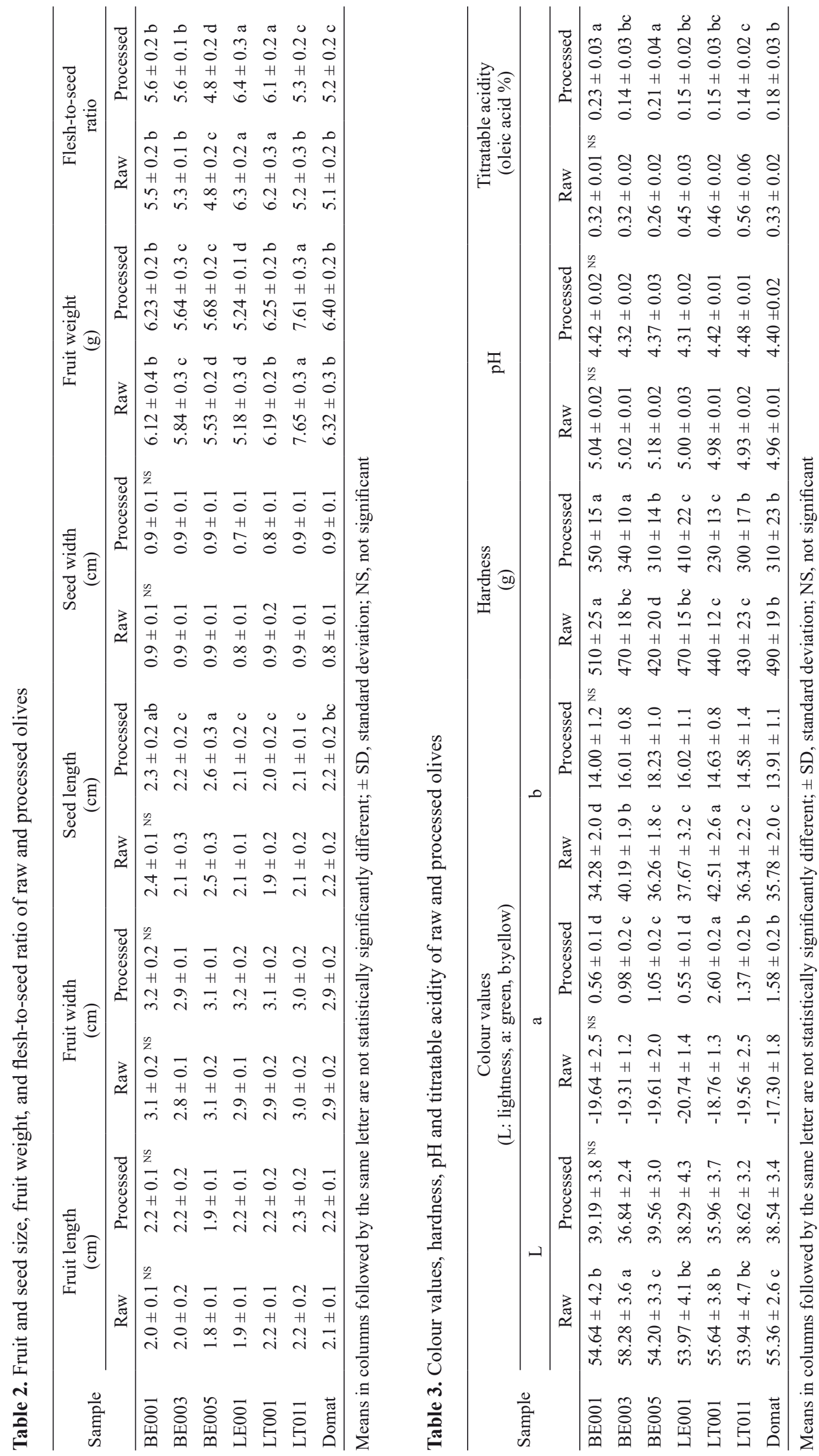




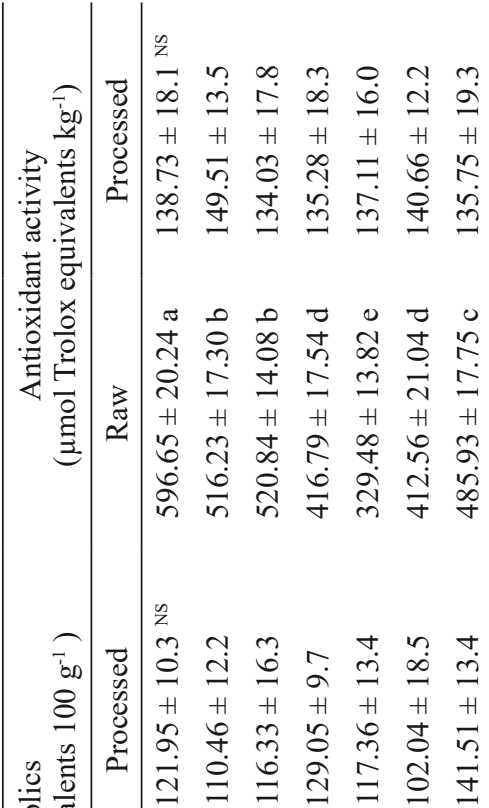

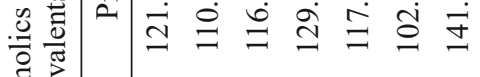

$\frac{\bar{a}}{2} \bar{z}$

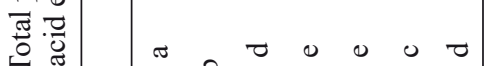

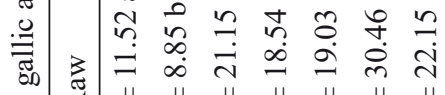
$\approx$ 而

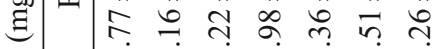

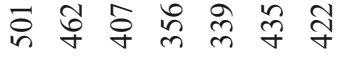

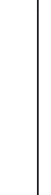

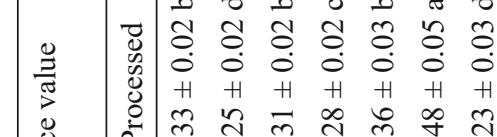

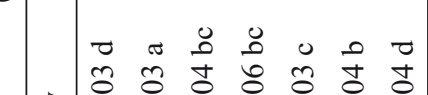

$\begin{array}{llllllll}3 & 0 & 0 & 0 & 0 & 0 & 0 & 0 \\ 0 & 0 & 0 & 0 & 0 & 0 & 0 \\ H & H & H & H & H & H & H\end{array}$

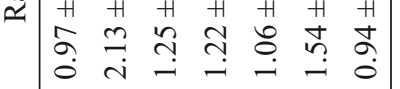

(a)

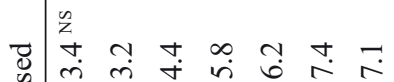

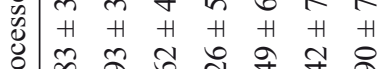

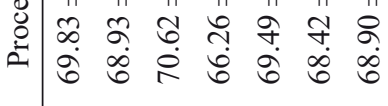

离

(1)

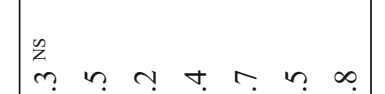

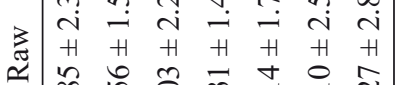

આ

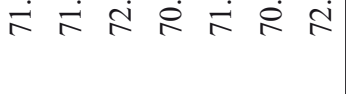

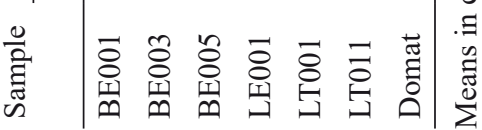

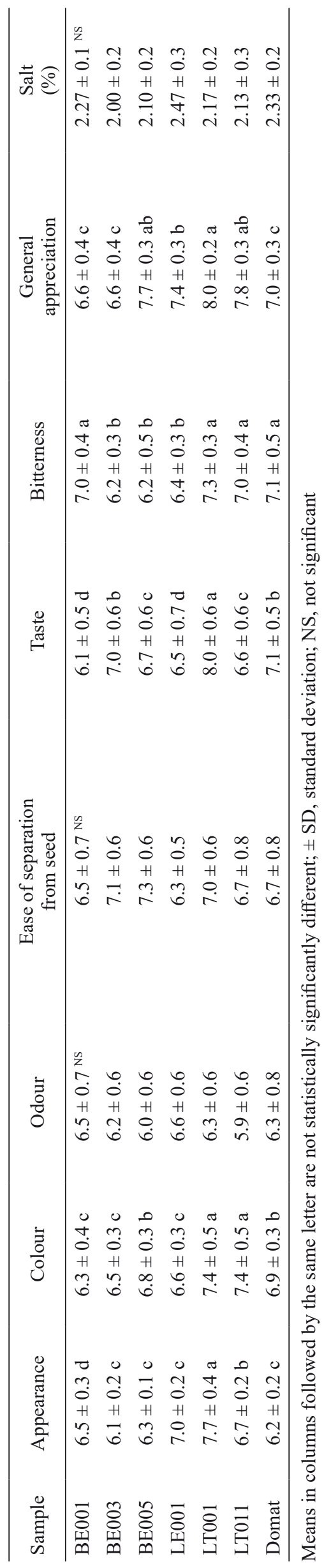


of polyphenols (Fadda et al., 2014). Polyphenols are one of the main human health components of olives and strongly affect the sensory properties of olive fruits (Sousa et al., 2008; Malheiro et al., 2011). When oleuropein absorbance values of raw and processed olives were compared, a 66.04 $-78.57 \%$ reduction was determined, whereas the losses in total phenolic content and antioxidant activity in the processed olives were in the ranges $63.84-76.10 \%$ and $65.91-76.75 \%$, respectively. LT001 showed a lesser loss of oleuropein absorbance and antioxidant activity than the others. On the other hand, LT001 showed the second lowest loss of total phenolic content after LE001. The salt content of olive samples was lower than the results of Ünal and Nergiz (2003) and Piga and Agabbio (2003) for green table olives. This difference is most likely caused by the salt content and olive/brine ratio of the brine solution used during processing in different studies. The total phenolic content and antioxidant activity of the processed olive samples were determined to be in the ranges 102.04-141.51 mg gallic acid equivalents $100 \mathrm{~g}^{-1}$ and 134.03-149.51 $\mu$ mol Trolox equivalents $\mathrm{kg}^{-1}$. These values were lower than those reported by Arroyo-López et al. (2007) and Malheiro et al. (2011). The oleuropein absorbance values of the processed olives were in agreement with those reported by Savas and Uylaser (2013) for table olives of the cultivar 'Domat'.

In this study, olives were processed using the same method, but their appearance, colour, odour, taste, bitterness and general appreciation showed statistically significant differences because of genetic factors. Sensory evaluation scores of processed olives are given in Table 5. The taste and bitterness results for the olive samples were similar to the results of Galán-Soldevilla et al. (2013) and Lanza and Amoruso (2016). Olives of LT001, LT011 and BE005 had a higher general appreciation score than those of the cultivar 'Domat', which was used for comparison. LT001 had the highest scores for appearance, colour, taste, bitterness and general appreciation characteristics. On the other hand, BE001 had the lowest score for these characteristics except bitterness.

In this research, olives were harvested when their maturation index was 1.1-1.3, which is recommended for green table olive production (Kailis and Harris, 2007), and processed by the same debittering and spontaneous fermentation methods. These processes should be effective in producing high scores for odour and ease of seed separation. The ease of seed separation from the flesh and odour are mostly affected by ripening and processing conditions rather than genetic factors and that is why statistical differences were not detected in the sensory evaluation. Colour and general appreciation scores were higher than the results of Savas and Uylaser (2013), who processed 'Domat' olives by the same method as in this study.

\section{CONCLUSIONS}

In this research, important table olive characteristics of raw and processed olives of candidate cultivars and the cultivar 'Domat' were determined. The candidate cultivars had been obtained under a crossbreeding project, whereas olives of the cultivar 'Domat' are widely produced in Turkey as green scratched olives. The results of this study showed that raw and processed olives of the genotypes LE001, LT001 and LT011 had better table olive characteristics (fruit weight, phytochemical and sensory) than the others. Therefore, these genotypes have the potential for registration as new cultivars for the production of scratched green table olives.

\section{FUNDING}

This research was done in the context of "Determination of Table Olive Properties of Some Hybrid Type" project, which was funded by Turkey's Ministry of Food, Agriculture and Livestock, General Directorate of Agricultural Research and Politics.

\section{AUTHOR CONTRIBUTIONS}

Y.O, N.A.T, A.O, E.G, M.E.A and S.E - equally contributed to the experimental design, analytical measurements, statistical analysis and manuscript writing.

\section{CONFLICT OF INTEREST}

Authors declare no conflict of interest.

\section{REFERENCES}

Anonymous, 2014. Table Olive Communiqué, Turkish Food Codex Regulation, Published in date and number: 23.08.2014-29097, Communiqué No: 2014/33.

Aponte M., Ventorino V., Blaiotta G., Volpe G., Farina V., Avellone G., Moschetti G., 2010. Study of green Sicilian table olive fermentations through microbiological, chemical and sensory analyses. Food Microbiol. 27(1), 162-170. 
ArJi I., Bahmanipour F., 2014. Adaptation ability of some olive cultuvars and genotypes in Ilam Province. Seed Plant Improvment J. 30(4), 761-775.

Arroyo-López A., Durán-Quintana M.C., Romero C., Rodríguez-Gómez F., Garrido-Fernández A., 2007. Effect of storage on the sugars, polyphenols, color, and microbiological changes in cracked Manzanilla-Aloreña olives. J. Agric. Food Chem. 55, 7434-7444.

Baldoni L., Belaj A., 2009. Olive. In: Oil Crops. J. Vollmann and I. Rajcan (Eds), Springer, Berlin, Germany, 397-421.

Bautista-Gallego J., Arroyo-López F.N., DurÁnQuintana M.C., Garrido-Fernández A., 2010. Fermentation profiles of Manzanilla-Alorena cracked green table olives in different chloride salt mixtures. Food Microbiol. 27, 403-412.

Bautista-Gallego J., Arroyo-López F.N., LópezLópez A., Garrido-Fernández A., 2011. Effect of chloride salt mixtures on selected attributes and mineral content of fermented cracked Aloreña olives. LWT 44(1), 120-129.

Belaj A., Munoz-Diez C., Baldoni L., Satovic Z., Barranco D., 2010. Genetic diversity and relationships of wild and cultivated olives at regional level in Spain. Sci. Hortic. 124, 323-330.

Bellini E., Giordani E., Rosati A., 2008. Genetic improvement of olive from clonal selection to crossbreeding programs. Adv. Hort. Sci. 22, 73-86.

Benjak A., Ercisli S., Vokurka A., Maletic E., Pejic I., 2005. Genetic relationships among grapevine cultivars native to Croatia, Greece and Turkey. Vitis 44(2), 73-77.

BOE, 2001. Boletín Oficial del Estado. Real Decreto 1230/2001. 2001. Reglamentación técnico-sanitaria para la elaboración, circulación y venta de las aceitunas de mesa. BOE núm 279, 21/11/2001, 4258742594.

Castro-Garcia S., Rosa U.A., Gliever C.J., Smith D., Burns J.K., Krueger W.H., Glozer K., 2009. Video evaluation of table olive damage during harvest with a canopy shaker. HortTechnology 19(2), 260-266.

El-Soaly I.S., 2008. Some physical and mechanical properties of olive fruits in (Ryayna-Khrian-Libyan Arab). Egypt J. Agr. Eng. 25(3), 899-909.

ERCISLI S., 2004. A short review of the fruit germplasm resources of Turkey. Genet. Resour. Crop Evol. 51, 419-435.

Ercisli S., Esitken A., 2004. Fruit characteristics of native rose hip (Rosa spp.) selections from the Erzurum Province of Turkey. New Zeal. J. Crop Hort. 32, 51-53.

Esti M., Cinquanta L., La Notte E., 1998. Phenolic compounds in different olive varieties. J. Agric. Food Chem. 46: 32-35.

Fadda C., Del Caro A., Sanguinetti A.M., Piga A., 2014. Texture and antioxidant evolution of naturally green table olives as affected by different sodium chloride brine concentrations. Grasas y Aceites 65(1), $\mathrm{e} 002$.

Galán-Soldevilla H., Ruiz Pérez-Cacho P., 2010. Sensory characterization of Aloreña olives. Universidad de Córdoba, Córdoba (Spain). Private report to the Manzanilla-Aloreña industrial sector.

Galán-Soldevilla H., Ruiz Pérez-Cacho P., Hernández Campuzano J.A., 2013. Determination of the characteristic sensory profiles of Aloreña tableolive. Grasas y Aceites 64(4), 442-452.

Hassan H.E., El-Rahman A.A., Attia M.M., 2011. Color properties of olive fruits during its maturity stages using image analysis. AIP Conference Proceedings 1380(1), 101-106

Jenks M.A., Bebeli P., 2011. Breeding for Fruit Quality. John Wiley \& Sons, Inc., Hoboken, NJ, USA.

KaILIS S.G., Harris D., 2007. Table olive processing: general aspects. In: Producing Table Olives. S.G. Kailis and D. Harris (Eds), Landlinks Press, Australia.

Kamiloglu O., Ercisli S., Sengul M., Toplu C., Serce S., 2009. Total phenolics and antioxidant activity of jujube (Zizyphus jujube Mill.) genotypes selected from Turkey. Afr. J. Biotechnol. 8(2), 303-307.

LANZA B., 2013. Abnormal fermentations in tableolive processing: microbial origin and sensory evaluation. Front. Microbiol. 4, 91-95.

Lanza B., Amoruso F., 2016. Sensory analysis of natural table olives: Relationship between appearance of defect and gustatory-kinaesthetic sensation changes. LWT 68, 365-372.

León L., De La Rosa R., Gracia A., Barranco D., Ar L., 2008. Fatty acid composition of advanced olive selections obtained by crossbreeding. J. Sci. Food Agric. 88(11), 1921-1926.

Malheiro R., Sousa A., Casal S., Bento A., Pereira J.A., 2011. Cultivar effect on the phenolic composition and antioxidant potential of stoned table olives. Food Chem. Toxicol. 49, 450-457.

Mikulic-Petkovsek M., Slatnar A., Schmitzer V., Stampar F., Veberic R., Koron D., 2013. Chemical profile of black currant fruit modified by different degree of infection with black currant leaf spot. Sci. Hortic. 150, 399-409.

Mikulic-Petkovsek M., Ivancic A., Todorovic B., Veberic R., Stampar F., 2015. Fruit phenolic composition of different elderberry species and hybrids. J. Food Sci. 80, C2180-C2190.

Milivojevic J., Slatnar A., Mikulic-Petkovsek M., Stampar F., Nikolic M., Veberic R., 2012. The influence of early yield on the accumulation of major taste and health related compounds in black and red currant cultivars (Ribes spp.). J. Agric. Food Chem. 60, 2682-2691.

OzDEMIR Y., Guven E., Ozturk A., 2014. Understanding the characteristics of oleuropein for table olive processing. J. Food Process. Technol. 5, 1-6.

Panagou E.Z., Hondrodimou O., Mallouchos A., Nychas G.J.E., 2011. A study on the implications 
of $\mathrm{NaCl}$ reduction in the fermentation profile of Conservolea natural black olives. Food Microbiol. 28, 1301-1307.

Piga A., Agabbio M., 2003. Quality improvement of naturally green table olives by controlling some processing parameters. Ital. J. Food Sci. 15, 259-268.

Rallo L., Barranco D., De La Rosa R., LeÓn L., 2008. 'Chiquitita' olive. HortScience 43(2), 529-531.

Rallo P., Jiménez R., Morales-Sillero A., Casanova L., Paz Suarez M., 2012. Evaluation of table-olive quality parameters in progenies obtained by crossbreeding. Acta Hortic. 949, 527-531.

SAhIN I., KORUKLUOĞLU M., GURBUZ O., 2002. Different cultivar, yeast and lactic starter use in brined black table olive production and effects of some additives on fermentation period and product quality. Proc. Turkey $7^{\text {th }}$ Food Engineering Conference, 22-24 May, Ankara, 203-212.

SAKAR E, Unver H., 2016. Molecular characterization of ancient olive genotypes from Hatay province in Turkey. Turk. J. Agric. For. 40, 795-801.

Sánchez Gómez A.H., Garcia Garcia P., Rejano NAVARro L., 2006. Elaboration of table olives. Grasas y Aceites 57(1), 86-94.

SARIDAS M.A., KAFKaS N.E., ZarifiKhosRoshahi M., Bozhaydar O., Kargi S.P., 2016. Quality traits of green plums (Prunus cerasifera Ehrh.) at different maturity stages. Turk J Agric. For. 40, 655-663.

SaVAS E., Uylaser V., 2013. Quality improvement of green table olive cv. 'Domat' (Olea europaea 1.) grown in Turkey using different de-bittering methods. Not. Bot. Horti. Agro. Cluj-Napoca 41(1), 269-275.

Sorkheh K., Khaleghi E., 2016. Molecular characterization of genetic variability and structure of olive (Olea europaea L.) germplasm collection analyzed by agromorphological traits and microsatellite markers. Turk. J. Agric. For. 40, 583 596.

Sousa A., Ferreira I.C.F.R., Barros L., Bento A., Pereira J.A., 2008. Effect of solvent and extraction temperatures on the antioxidant potential of traditional stoned table olives "alcaparras". LebensmWiss. Technol. 41, 739-745.

Thaipong K., Boonprakob U., Crosby K., CisnerosZevallos L., Byrne D.H., 2006. Comparison of ABTS, DPPH, FRAP and ORAC assays for estimating antioxidant activity from guava fruits extracts. J. Food Comp. Anal. 19, 669-675.

Tosun M., Ercisli S., Karlidag H., Sengul M., 2009. Characterization of red raspberry (Rubus idaeus L.) genotypes for their physicochemical properties. J. Food Sci. 74(7), C575-C579.

TS 774., 1992. Turkish Standards Institute, Turkish Table Olive Standard. Ankara, Turkey.

Usenik V., Fabric J., Stampar F., 2007. Sugars, organic acids, phenolic composition and antioxidant activity of sweet cherry (Prunus avium L.). Food Chem. 107, $185-192$.

Ünal K., Nergiz C., 2003. The effect of table olive preparing methods and storage on the composition and nutritive value of olives. Grasas y Aceites 54(1), 71-76.

Varol N., Erten L., Turanli T., 2009. Olive. Ministry of Agriculture 52, Ankara, Turkey, 330.

YAZICI K., SAHIN A., 2016. Characterization of pomegranate (Punica granatum L.) hybrids and their potential use in further breeding. Turk. J. Agric. For. 40, 813-82.

Received July 29, 2017; accepted March 5, 2018 